\title{
CATEGORIAS ANALÍTICAS DO ESPAÇO E TURISMO: $O$ EXEMPLO DA FORTALEZA DE SANTA CRUZ, NITERÓI/RJ'
}

\author{
Miguel ÂNGELo RiBEIRO \\ Universidade Estadual Rio de Janeiro
}

Estátuas, templos, memoriais e outras formas simbólicas grandiosas são representações materiais de eventos passados, que compõem a paisagem de certos espaços públicos da cidade.

São intencionalmente dotados de sentido político, comunicando mensagens associadas à celebração, contestação ou à memorialização, visando o presente e o futuro. São, contudo, submetidos a diversas interpretações (CORREA, 2005).

\section{Considerações Iniciais}

Na dinâmica espacial da cidade de Niterói, o processo de mudança de função dos fixos sociais têm sido extraordinário. Residências unifamiliares, prédios e até mesmo, fortificações militares, verdadeiras monumentalidades, foram refuncionalizadas, passando por um processo de turistificação.

\footnotetext{
${ }^{1}$ Um primeiro texto foi elaborado em co-autoria com o geógrafo Luciano Castellano Pereira intitulado "Geografia e Turismo: o exemplo da Fortaleza de Santa Cruz, Niterói/RJ". Nesta nova versão gostaria de agradecer imensamente à geógrafa Ana Maria Fernandes da Costa pela leitura minuciosa do texto e pelas valiosas sugestões.
} 
Convém ressaltar que a cidade enquanto resultado da transformação da natureza em bens culturais mediante a ação humana é mencionada por Machado (2003)

como uma verdadeira 'arena', onde o confronto de estratégias e o conflito de interesses diversos promovem rupturas, mudanças e persistências na paisagem urbana (LEFÈBVRE, 1999). Tal complexidade pode ser constatada a todo instante, na materialização de diferentes formas $e$ relações que evidenciam a especificidade de cada sociedade em um determinado período (p.4).

Atualmente a cidade, em decorrência de mudanças políticas, econômicas e culturais na sociedade, constitui-se no lócus preferencial para a atuação de diversos agentes e atores, contribuindo para um fantástico incremento das dinâmicas que atuam na reconfiguração do espaço urbano. Neste contexto, a presente pesquisa envolve uma fortaleza militar, a Fortaleza de Santa Cruz, atualmente tendo por serventia as atividades de lazer e de turismo.

Posto isto, o objetivo que permeia a presente pesquisa é utilizar a respectiva Fortaleza como foco de análise, ressaltando a importância deste fixo social enquanto atração turística e de lazer, e que inclui a cidade de Niterói no circuito destas atividades, complementares à cidade do Rio de Janeiro; além de abordar conceitos e categorias analíticas, oriundos das ciências sociais, principalmente provenientes da Geografia, pertinentes ao estudo das atividades em tela. Cumpre destacar que os conceitos e categorias analíticas abordados serão: forma e função (SANTOS, 1985, 1996); fixo social (SANTOS, 1988); centralidade (MELLO, 1995); monumentalidade e monumento (RIEGL, 1984; LE GOFF, 1985; HARVEY,1996; CHOAY, 2001; RODRIGUES, 2000 e 2001, FERNANDES, 2004, MENESES, 2004 e CORREAA, 2005); patrimônio histórico e cultural (BARRETO,2001; KOTHER, 2001 e YÁZIGI, 2003); e símbolo (TUAN,1980; COSGROVE,1998; EPSTEIN, 2001; BONNEMAISON, 2002; MELLO, 2003 e LIMA E SILVA, 2005).

O presente estudo empenha-se, portanto, em analisar o processo experimentado pela Fortaleza de Santa Cruz, localizada no bairro de Jurujuba, em Niterói/RJ, assumindo diferentes funções (tarefa, atividade ou papel a ser desempenhado pelo objeto criado [CORRÊA, 1986]), durante a sucessão temporal desde sua construção até os dias atuais, como também, tratar a partir deste fixo social (coisas fixas que nos dão o processo imediato do trabalho; os próprios instrumentos de trabalho e forças produtivas em geral, incluindo a massa dos homens [SANTOS, 1988, p.77]) de sua importância para a atividade turística e de lazer.

Para que possamos analisar a forma (aspecto visível, exterior de um objeto [CORRÊA, 1986, p.76]) atual - da Fortaleza de Santa Cruz - a fim de vislumbrar a lógica de sua edificação, devemos recorrer à sua historicidade, com o objetivo de desvendar a que se presta sua materialidade no dado momento em que se encontra. 
Categorias Analíticas do Espaço e Turismo: O Exemplo da Fortaleza de Santa Cruz, Niterói/RJ Visto isto, torna-se de fácil entendimento a função atribuída a tal forma, por sua localização estratégica.

Dessa forma, o presente artigo encontra-se estruturado em três partes. A primeira aborda o passado e o presente da Fortaleza de Santa Cruz; a segunda contempla a relevância histórica da referida Fortaleza, desde o seu estabelecimento em 1555 até os dias atuais; enquanto a terceira parte procura enfocar as diferentes funções exercidas pelo fixo social em tela, além de tratar de conceitos das ciências sociais e, principalmente, da Geografia, pertinentes ao estudo da atividade turística.

\section{A Fortaleza de Santa Cruz: Passado e Presente}

A Fortaleza de Santa Cruz, hoje ocupando função turística, de lazer e militar, encontra-se na antiga capital fluminense (a cidade de Niterói), na entrada da Barra da Baía de Guanabara à frente dos morros do Pico e do Macaco, com uma área construída de mais de sete mil metros quadrados. Sua localização foi eminentemente estratégica a propósito de defesa do território que, segundo Rahy (1999). processouse no contexto de colonização a que se submeteram as terras brasileiras, a partir do século XVI:

(...) resultante da iniciativa do Estado português, associado a uma burguesia mercantilista, interessado, de um lado, na garantia da posse deste território de além-mar e, de outro na exploração comercial, isto é, na busca de metais preciosos e na obtenção de altos lucros com a venda de mercadorias tropicais demandadas pela Europa, que, por motivos mesológicos, não as poderia produzir(p. 37).

Neste contexto, a cidade do Rio de Janeiro fundada em 1565 e localizada na Baía de Guanabara, posteriormente transferida para o Morro do Castelo em 1567 encontra-se no bojo de tal estratégia. Cumpre mencionar que a estratégia portuguesa por outro lado visava a defesa do território em decorrência das incursões estrangeiras que ocorreram a partir de 1555, como a de franceses, nas ilhas da Baía de Guanabara e arredores, tentando fundar aqui a França Antártica (SILVA, 2001). É neste momento que Salvador Corrêa de Sá, após a expulsão dos franceses, aproveitandose dos canhões abandonados pelos idealizadores da França Antártica e constatando a excelência desta posição para a defesa da baía ampliou a fortificação que segundo Maryan (1997) transformou-se no principal ponto de defesa da Baía de Guanabara recebendo a denominação de Nossa Senhora da Guia e que a partir de 1632, passou a denominar-se Fortaleza de Santa Cruz da Barra e, em 1939, a chamar-se Fortaleza de Santa Cruz, quando foi tombada pelo Patrimônio Histórico Nacional. Sua denominação é uma homenagem ao primeiro nome atribuído ao Brasil, quando de 
sua descoberta pelos portugueses. Além da Fortaleza de Santa Cruz, objeto de nosso estudo, outros fortes e fortalezas situados em Niterói, ou no Rio de Janeiro tinham por objetivo, como mencionado, proteger a entrada da Baía de Guanabara, além desta cidade.

Segundo Silva (2001), nas proximidades do Morro do Castelo foi construído o Forte de São Januário e na entrada da Baía de Guanabara, complementando a referida fortaleza foi erguida Laje, na ilha de mesmo nome. Tais monumentos fizeram com que a cidade do Rio de Janeiro apresentasse a função militar, persistindo com a construção de inúmeros fixos com tal serventia, podendo-se mencionar: Forte Marechal Floriano Peixoto (Niterói, século XVI), Forte Tamandaré (Rio de Janeiro, século XVI), Fortaleza da Conceição (Rio de Janeiro, 1715), Forte São Luiz(Niterói, 1775), Forte Duque de Caxias (Rio de Janeiro, 1769), Forte do Imbuí (Niterói, 1863), e Forte Barão do Rio Branco (Niterói, possivelmente no ano de 1567). Cabe fazer referência, para melhor entendimento do complexo de fortificações instalado em Niterói e no Rio de Janeiro, segundo MARYAN (1997), quanto à diferenciação entre os vocábulos Forte e Fortaleza. Para a referida autora o Forte, é composto por uma ou mais baterias de artilharia localizadas na mesma obra, enquanto a Fortaleza, é composta por duas ou mais baterias localizadas em obras independentes e com grande intervalo entre elas.

Desse modo, apropriando-se das palavras de LESSA (2000), "a Baía de Guanabara é simplesmente uma maravilha, não apenas por sua beleza natural, mas sobretudo do ponto de vista da tecnologia militar". O autor, ainda menciona, que apesar da baía possuir um perímetro de cerca de 140 quilômetros, exibe uma barra de apenas 1600 metros de largura, limitada pelos costões do Pão de Açúcar e de Santa Cruz e entre essas duas feições geográficas está a Ilha de Laje, no meio da barra. Sendo assim, pode-se afirmar em consonância com as palavras de Lessa (2000), que o Rio de Janeiro, nos seus primórdios, ostentava profunda vocação militar em decorrência de sua posição estratégica adequada à este tipo de função.

\section{A Relevância Histórica da Fortaleza de Santa Cruz}

Podemos entender sua emergência enquanto principal área de defesa ao possível intento de invasão de suas terras, esta função de proteção de sua área territorial fora a que mormente marcou o monumento em tela e perdurou neste papel de defesa costeira durante bastante tempo. Tombada pelo IPHAN, desde 1939, como patrimônio histórico, mais tarde passou a exercer função turística, em decorrência de sua importância histórico-cultural².

\footnotetext{
${ }^{2}$ www.angelfire.com/az/mapao/stcruz.html
} 
O estabelecimento da Fortaleza em questão ocorreu em 1555 pelo francês Villegaignon que comandou a invasão francesa ao Rio de Janeiro, instalando neste local duas peças de artilharia. Após a campanha de expulsão dos franceses pelos portugueses em 1567, a referida fortificação recebe obras de melhoramento pelo então Governador Geral Mem de Sá (1558-1572), e através de seu sobrinho Correia de Sá passa a denominar-se Nossa Senhora da Guia. Em 1612, na sucessão de reformas, encontrava-se equipada com 20 peças; e em 1632 recebe a alcunha de Fortaleza de Santa Cruz da Barra. Cerca de um século mais tarde, com a atividade mineira, nas Minas Gerais, o embarque para comercialização das pedras preciosas necessitava de proteção e o Vice-Rei Antonio Álvares ordena, então, a reforma que ampliará seu poder de ação, sendo que em 1730 a mesma agregava 135 peças de artilharia. Cumpre mencionar que a sua função de defesa era integrada ao Forte do Pico e às Baterias da Praia de Fora e da Boa Viagem, diretamente subordinadas à Fortaleza ${ }^{3}$. Por razões econômicas, após a independência do Brasil no período de crises regenciais, seu poder bélico fora reduzido à metade, porém no Império, e posteriormente com a República, sua força armamentista é reforçada novamente, recebendo equipamentos modernos em 1871, marcando sua última remodelação.

Estabelecido seu processo de reestruturação, impende mencionar a atividade exercida pela Fortaleza no propósito de defesa territorial, sendo sua instalação decisiva para a história de domínio e preservação do Rio de Janeiro pelos portugueses. Neste contexto, no exercício de sua função estratégica impediu a entrada do corsário holandês Olivier Van North (1599) nas terras da Baía de Guanabara, repetindo o feito em 1710 na investidura contra a tropa de navios do francês Duclerc que tentara invadir a referida cidade.

O mesmo feito não repetiu-se contra Duguay-Trouin, que ao invadir as terras cariocas encontrou a Fortaleza desguarnecida por ordem do Governador Castro Morais; conseqüentemente a cidade ficou ocupada pelos franceses até o ano de 1711 quando de sua retirada.

O referido fixo social, também foi utilizado como presídio no século XIX, aprisionando figuras importantes da história nacional, tais como: José Bonifácio, Bento Gonçalves e Euclides da Cunha. Sua ação coercitiva atuou também, no século XIX, na Revolta da Armada (1893), e no século XX, na Revolta Tenentista (1922), sendo seu último disparo, contra o cruzador Tamandaré em $1955^{4}$. Cumpre fazer menção, que no período da ditadura militar, a Fortaleza abrigou presos políticos, exercendo a função de presídio do exército.

Em 1983, a Fortaleza em questão passou a sediar o $8^{\circ}$ Grupo de Artilharia de Costa Motorizado ( $\left.8^{\circ} \mathrm{GACosM}\right)$, transferido do bairro do Leblon, na cidade do Rio

\footnotetext{
${ }^{3}$ www.bndes.gov.br/noticias/not35.asp

${ }^{4}$ www.bndes.gov.br/noticias/not35.asp
} 
de Janeiro, assumindo o aquartelamento do extinto presídio do exército. Em 1984, por decisão ministerial, recebeu o Comando do Grupo e Bateria de Comando e Serviço, permanecendo as duas Baterias de Canhões na referida Fortaleza e nos Fortes localizados no bairro de Jurujuba em Niterói e em 1987 deixou de sediar o $8^{\circ}$ GACosM. Em maio de 1998, foi recebido pelo Grupo o sistema de Defesa de Costa Astros II, sendo criada a Bateria de Lançadores Múltiplos de Foguetes, no Forte do Imbuhy. Em 1999, a unidade recebeu a denominação de Grupo Presidente Geisel em homenagem ao seu ex-Comandante ${ }^{5}$. Nos diferentes recortes temporais, identificamos várias reformas e mudanças de funções exercidas pela Fortaleza de Santa Cruz. Hoje com a construção da malha viária de acesso à mesma, e a preservação de sua arquitetura, verdadeira monumentalidade, através de sua fachada e de seu espaço interno (LEFÉBVRE, 1999), esta desenvolve importante papel de centralidade turística, para a metrópole carioca e mais especificamente para o município de Niterói, recebendo visitantes e turistas nacionais e internacionais, e concretizando-se enquanto Patrimônio Histórico da Memória Nacional.

\section{Fortaleza de Santa Cruz: da condição de defesa à condição de atração turística}

A Fortaleza em questão passou por diferentes funções, desde o seu estabelecimento em 1555 até os dias atuais. Cumpre mencionar que a mesma apresentou a função de defesa até 1955; posteriormente passou a ser base do $8^{0}$ Grupo de Artilharia de Comando de Costa Motorizado, exercendo, conseqüentemente, o papel de unidade militar do Exército brasileiro. Tombada pelo IPHAN, como patrimônio histórico desde 1939, passou a exercer a função turística, em decorrência de sua importância histórico-cultural, em superposição à sua função militar, atividades estas, verificadas hodiernamente.

Neste contexto, a Fortaleza de Santa Cruz é assim, um fixo social (SANTOS, 1988), uma construção elaborada pelo homem, plena de centralidade (MELLO, 1995), ou seja, é um lugar central, em decorrência de atrair militares e visitantes, apresentando uma área de abrangência que extrapola os limites do município niteroiense. Mello (1995:23) aponta:

A centralidade assume as mais diversas facetas em diferentes escalas. Uma cabine telefônica, um cinema, um templo ou endereço domiciliar são lugares centrais porque atraem usuários e irradiam idéias e significados.

\footnotetext{
${ }^{5}$ www.nikitinautas.com.br
} 
Categorias Analíticas do Espaço e Turismo: O Exemplo da Fortaleza de Santa Cruz, Niterói/RJ

O autor ainda expressa em seu artigo que existem outros tipos de centralidades não tradicionais e que eclodem cotidianamente, e prosseguindo, afirma:

Os lugares centrais não estão restritos àqueles definidos pela Escola de Ecologia Humana de Chicago ou pela Teoria dos Lugares Centrais, amplamente utilizados pela geografia (p.23-24).

Para os geógrafos um lugar central é conceituado como ponto de concentração e irradiação de fluxos financeiros, administrativos, comerciais, sociais etc. Para estes geógrafos, a centralidade é a medida de importância do lugar enquanto lugar central, expressa pela magnitude dos bens e serviços oferecidos e pela área de abrangência ou de atuação desse lugar (MELLO, 1995). Mas, como aponta o referido autor, há uma pluralidade de perspectivas sobre a questão da centralidade que pode ser analisada por diferentes correntes, escalas e dimensões.

Em seu estudo calcado na vertente humanística, o autor em tela apresenta um amplo leque de centralidades vivenciada pelos indivíduos e grupos sociais, tendo como recorte espacial a cidade do Rio de Janeiro, e no qual procuramos transpor para o nosso objeto de estudo, a Fortaleza de Santa Cruz, a mesma evidencia diferentes centralidades que se superpõem, a saber: militar, turística e de lazer em função de sua importância histórico-cultural.

A centralidade deste fixo social vem no bojo de sua forma - aspecto visível, exterior, de um objeto (SANTOS, 1985) - representada pela fortificação dotada de uma série de elementos bélicos, como também de outros elementos fixos em seu interior. Para Santos (1996, p.72), discorrendo sobre as formas aponta:

[...] em todos os momentos as formas criadas no passado têm um papel ativo na elaboração do presente e do futuro. A história da cidade é a da suas formas, não como um dado passivo mas como um dado ativo.

Esta forma expressa uma monumentalidade fantástica, destacando-se na paisagem da Baía de Ganabara.

A temática relacionada a monumentos e à monumentalidade, recentemente tem sido analisada por parte de alguns cientistas sociais, entre eles incluídos os geógrafos, oriundos, principalmente, da chamada nova geografia cultural. A partir da década de 1990, este conceito passou a ser investigado mas, no entanto, tais estudos, de modo geral, não chegaram a aprofundar o tratamento conceitual, limitando-se à análise de casos pontuais (RODRIGUES, 2000 e 2001). Sendo assim, segundo diferentes autores, dentre eles Riegl (1984), Le Goff (1985), Harvey (1996), Choay (2001), Rodrigues (2000 e 2001), Meneses (2004) e Corrêa (2005), entre outros, discutem que monumentos apresentam diferentes significados. 
Para Riegl (1984), tais edificações apresentam caracteres variados conforme o avanço da História, chegando ao século XX tratado não mais pelos rígidos valores do classicismo, mais por um questionável valor artístico, enquanto para Le Goff (1985), monumentos se expressam em documentos, pois guardam um legado à memória coletiva das gerações futuras. Já Choay (2001), apropriando-se de Quatremère de Quincy, aponta:

aplicadas às obras de arquitetura, essa palavra designa um edifício construido para eternizar a lembrança de coisas memoráveis, ou concebido, erguido ou disposto de modo que se torne um fator de embelezamento e de magnificência das cidades (p.19).

A autora ainda aponta, "o monumento se impõe à atenção sem pano de fundo, atua no instante, substituindo seu antigo status de signo pelo de sinal" (p.20). Mas, todo monumento encerra em si uma monumentalidade, e nela está implícita uma carga ideológica, uma carga de poder. Neste contexto, Harvey (1996), criticando a estética urbana modernista do pós-guerra, afirma:

O capital corporativo se apropriava alegremente de todo artificio modernista do livro de arquiteto para dar continuidade à prática da construção de monumentos que se elevam cada vez mais no horizonte como simbolos do poder corporativo (p.73).

Hodiernamente, para Meneses (2004), a idéia de monumento apresenta, pelo menos, dois sentidos. Um corresponde ao seu significado em latim - monumentum, vocábulo derivado de monere ("lembrar"). Sendo assim, monumento é aquilo que memoriza, traz à lembrança, algo que se quer guardar, algo que é digno de memória. $\mathrm{O}$ monumento tem um caráter afetivo em decorrência de estar atrelado a um determinado grupo social ou comunidade, buscando tornar viva a memória de algo importante e identitário socialmente. Neste sentido, o monumento, necessariamente tem como mediadores a memória construída e a história. O segundo sentido para a idéia de monumento é que o mesmo representa uma construção que não tem função memorial explicita e sim a de exaltar a beleza ou técnica de seu tempo presente. Este sentido remonta ao Renascimento, associando a idéia de beleza e criatividade engenhosa à celebração memorial.

Cumpre fazer referência, que o conceito de monumento não se limita às obras arquitetônicas ou esculturais tal como apreendidas pelo senso comum. Além destas, são considerados como monumentos também os vários tipos diferentes de documentos escritos e iconográficos, as obras de arte e todo e qualquer elemento ou objeto que expresse a atividade e o pensamento social de uma época (RIEGL, 1984; LE GOFF, 1985; CHOAY, 2001 e RODRIGUES, 2001). 
Categorias Analíticas do Espaço e Turismo: O Exemplo da Fortaleza de Santa Cruz, Niterói/RJ

Corrêa (2005, p.2) aponta que os monumentos apresentam "forte potencial para perpetuar antigas tradições, fazer parecer antigo o que é novo e representar valores que são passados como se fossem de todos".

Neste contexto, o conceito de monumento configura-se como fundamental e útil para alcançarmos uma definição e um entendimento maior sobre a monumentalidade. Porém, a monumentalidade, categoria abstrata que é inerente ao monumento (categoria concreta), também o transcende.

A monumentalidade está presente no monumento, mas vai mais além, mostrandose complexa se deixarmos de nos fixar somente à realidade empírica e imediata $\mathrm{e}$ começarmos a nos indagar, sobre o seu significado na construção do espaço, sua origem e seu papel social na história (RODRIGUES, 2001). Sendo assim, a Fortaleza de Santa Cruz insere-se nestes respectivos contextos, perdendo seu significado original e ganhando novo significado, e como afirma Riegl (1984), os monumentos atestam caracteres variados conforme o avanço da História, deixando a condição de caráter intencional, passando a ser avaliados por sua condição artística, no renascimento, tendo por base a estética classicista e chegando aos dias atuais, mais precisamente o século XX, e avaliados pelo seu valor artístico, mas "os monumentos intencionais ou não intencionais que transbordem e muito o seu tempo de existência serão reconhecidos por este próprio mérito, o de resistirem ao tempo" ( FERNANDES, 2004, s/p).

Cumpre mencionar que a monumentalidade da Fortaleza em questão é expressa também em seu interior, através de obras arquitetônicas que se apresentam distribuídas por três níveis diferenciados. Dentre estas obras podemos distinguir: 0 Pórtico, correspondendo a entrada principal; o Relógio de Sol; a Capela de Santa Bárbara e a Cova da Onça, no terceiro nível. No segundo nível encontram-se localizada a Bateria 2 de Dezembro, na qual estão as vinte Casamatas, abrigando as 20 peças de artilharia; o Corredor da Morte contendo salas de tortura, além da Masmorra e $o$ acesso à Cisterna. O primeiro nível, atualmente proibido para visitação, é constituído pela Bateria 25 de Março com 20 Casamatas, o Paredão de Fuzilamento e um Canhão interno. Atualmente, neste nível, suas dependências internas são utilizadas para cerimoniais.

Neste conjunto de formas identificadas nos três níveis mencionados, cumpre fazer referência à Capela de Santa Bárbara e as Baterias 2 de Dezembro e 25 de Março.

A Capela de Santa Bárbara segundo a Treviso Engenharia (s/d), construída em 1612, seu altar abriga a histórica imagem de Santa Bárbara, padroeira da artilharia, em madeira maciça, com 1,73 de altura, e ornada com pedras semi-preciosas. A Capela apresenta arquitetura do período jesuítico e tombada pelo patrimônio histórico nacional foi reerguida por Jacques Funck, engenheiro militar suíço em 1763, tendo sido alvejada durante a Revolta da Esquadra Brasileira. A Capela foi restaurada, em março de 1995, pelo comandante desta unidade militar, Cel. Bueno, destacandose na paisagem interior do primeiro piso da referida Fortaleza. 
A Bateria 2 de Dezembro, localizada no segundo nível, foi construída em 1875, no reinado de D. Pedro II. Esta Bateria é edificada quando foi construído o quartel sob a direção da Comissão de Melhoramento Material do Exército, idealizada pelo Major B.R. Gamboa, nela estando localizada o Paiol principal, abrigando 20 Casamatas, com respectivos canhões, enquanto a Bateria 25 de Março teve sua construção iniciada em 1863, com 20 casamatas e sua denominação é uma homenagem a data de promulgação da $1^{\text {a }}$ Constituição do Brasil em 1924, localizada no primeiro nível. Cumpre explicitar o significado simbólico do vocábulo Casamata. Esta denominação faz uma alusão a forma da referida construção, que a associa à uma casa "que mata".

Neste contexto, a Fortaleza de Santa Cruz em decorrência de sua monumentalidade é considerada um Patrimônio Histórico, em função de sua arquitetura, ou seja, da indiscutível presença de sua edificação como um ponto alto da realização humana. Trata-se na verdade do ambiente artificial, juntamente com um conjunto de produtos do sentir, do pensar e do agir humanos, tais como esculturas, pinturas, textos escritos, peças de valor etnológicos, arquivos e coleções bibliográficas, desenhos artísticos ou científicos, entre outros, que são geradores de uma cultura (BARRETO, 2001 e KOTHER, 2001).

O Patrimônio é um bem cultural, merecedor de tratamento e conservação adequados, com seu valor para o conhecimento de um local, de uma época, de estilo de vida, ou seja, representa o momento de uma sociedade, em um dado período de tempo. Sendo assim, uma rua, uma casa, um prédio, um Forte ou uma Fortaleza não são puramente funcionais. Esses elementos urbanos, verdadeiros fixos sociais, na expressão de Santos (1988), abrigam a memória e as experiências humanas significativas, marcando o espaço, como expressão das relações sociais. E, como aponta Barreto (2001, p. 103). "é através dos monumentos, da arquitetura, bens móveis que podemos nos transplantar nos séculos, passando por épocas diferentes, onde os mais diversos personagens se apresentam falando de sua história", e, neste contexto, aproveitando-se das idéias desta autora (2001, p.103), "a História está inserida no Patrimônio e o Patrimônio é o testemunho da História".

Kother (2001), discutindo a questão do Patrimônio Cultural, afirma que a partir da análise da trajetória e evolução deste conceito, que, segundo a Convenção de Paris, de 1972, engloba os monumentos, os conjuntos e os lugares notáveis, caracterizando-se por marcar a transmissão de uma historicidade, além do seu poder de ação como referencial na trajetória de vida dos povos, e traduzindo-se na memória da história oficial (e é o que o vai qualificar), além de sua estética vigente e da arte.

\footnotetext{
${ }^{6}$ Informações obtidas em visita à referida Fortaleza pelo soldado Régis do 80 Grupo de Artilharia de Costa Motorizado, em 20/08/2004.
} 
Categorias Analíticas do Espaço e Turismo: O Exemplo da Fortaleza de Santa Cruz, Niterói/RJ

Yázigi (2003), apropriando-se das idéias de Chastel citando Victor Hugo, aponta que:

um edificio possui duas características: seu uso e sua beleza. Seu uso pertence ao proprietário, sua beleza a todo mundo; logo, trata-se antes de ultrapassar do que destruir. Mas que isso, a instituição de um patrimônio monumental era indispensável para a criação de uma consciência nacional, de uma identidade que fosse motivo de orgulho, de exemplo de civilização [...] (p.57).

No Brasil, o conceito de Patrimônio Cultural está enraizado no Decreto-Lei número 25 de 30 de novembro de 1937, o qual, segundo Kother (2001, p. 110) expressa:

O Patrimônio Histórico e artístico nacional é constituído de bens móveis e imóveis existentes no país e cuja conservação seja de interesse público, seja por sua vinculação aos fatores memoráveis da História do Brasil, seja por seu excepcional valor arqueológico, etimológico, bibliográfico ou artístico.

Cumpre fazer referência, ao fixo social como símbolo no espaço e para os geógrafos do horizonte humanístico, como aponta Lima e Silva (2005, p.45):

os lugares são repletos de símbolos. Para Mello (2003) os lugares adquirem significados para os indivíduos por meio de laços afetivos tecidos no decorrer dos anos.

O símbolo, por excelência, "é uma parte que tem o poder de sugerir um todo" (TUAN, 1980, p.26).

Discutindo, ainda, sob um outro enfoque o conceito de símbolo Epstein (2001) aponta, a partir de Schaff, que os mesmos "são objetos materiais que representam noções abstratas" (p.77). Para este autor:

os simbolos desempenham papel importante na vida imaginativa. Eles revelam os segredos do inconsciente, conduzem a ação por caminhos que às vezes não são perfeitamente claros. A formação, o agenciamento e a interpretação dos símbolos interessam a muitas disciplinas: a História das civilizações e das religiões, a lingüística, a antropologia cultural, a crítica de arte, a psicologia profunda (2001, p. 66), além da ciência geográfica, entre outras. 
Bonnemaison (2002), refletindo sobre a cultura, indica a necessidade de aprofundar o papel do simbólico no espaço. Sendo assim, o autor menciona:

os simbolos ganham maior força e realce quando se encarnam em lugares. $O$ espaço cultural é um espaço geosimbólico, carregado de afetividade $e$ significações: em sua expressão mais forte, torna-se território-santuário, isto é, um espaço de comunhão com um conjunto de signos e de valores (p.111).

Para Lima e Silva (2005, p.45), comungando com a vertente humanística:

o símbolo contém ou contempla algo de maior expressão. E da mesma maneira, dependendo da pessoa, dos grupos sociais ou da população em geral qualquer elemento da natureza, artefato criado pelo homem, algo concebido no imaginário ou mesmo a cidade e a pátria podem se revestir de valores simbólicos [...]. Nesta linha de abordagem um símbolo é um repositório de significados.

Nesta concepção, Tuan (1980, p.166) assinala que os símbolos "emergem das experiências profundas que se acumulam através do tempo", enquanto para Cosgrove (1998, p.106), o símbolo "serve ao propósito de reproduzir normas culturais e estabelecer valores de grupos dominantes por toda uma sociedade". Por outro lado, este mesmo autor afirma que "em um mundo tão ricamente simbólico, os objetos e eventos assumem significados que para um estrangeiro podem parecer arbitrários" (p.120-121).

\section{Arremates}

A pesquisa em tela teve como recorte espacial a Fortaleza de Santa Cruz, procurando analisar a contribuição e aplicabilidade das ciências sociais e mormente a da geografia, através de seus conceitos e categorias. Neste sentido, podemos afirmar que um fixo social, da magnitude da referida Fortaleza, pleno de centralidade, monumentalidade, patrimônio cultural e símbolo, carregado de significados e afetividade é um produto turístico que exerce sobre o consumidor atração, uma vez que possui um forte caráter diferencial.

Hodiernamente nos contextos da Baía de Guanabara e do município de Niterói, o fixo em tela constitui-se em um importante ponto de atração e centralidade, em razão de suas diferentes funções exercidas, conduzindo ao seu espaço visitantes e turistas das mais diferentes classes sociais, provenientes principalmente do setor hoteleiro do Rio de Janeiro, no qual estão incluídos os turistas estrangeiros, em sua 
grande maioria, secundados por visitantes provenientes do Rio de Janeiro e, secundariamente, Niterói, perfazendo uma média de público anual registrada em 2003, da ordem de 40 a 50 mil pessoas ${ }^{7}$. Como aponta Silva (2001, p. 50):

trata-se de uma nova política - e estratégia - desempenhada pelos militares. Há um enorme capital fixo empregado na construção e preservação dos fortes em questão. Os militares postulam que a conservação e restauração desses fixos sociais podem ser efetivadas igualmente no oferecimento desses espaços à comunidade e aos turistas que desfrutam e propagam o papel histórico das Forças Armadas.

Nestas circunstâncias, a Fortaleza de Santa Cruz se associa ao conjunto dos fixos sociais restaurados e preservados em razão de seu legado, de sua memória e fiel às suas origens, enfim a uma arqueologia dos monumentos e do patrimônio histórico. Sendo assim, a refuncionalização da respectiva Fortaleza, para fins de lazer e turismo, torna-se um importante atrativo, marcando no espaço urbano niteroiense sua expressão de monumentalidade, criada pelo homem como símbolo de seus ideais, objetivos e atos, constituindo-se em um legado às gerações futuras, formando um elo entre passado, presente e futuro.

Por fim, podemos afirmar que a referida Fortaleza apresenta dimensões que a singularizam no espaço interno niteroiense, sendo elas: histórica, artística, cultural, arquitetônica, militar e geográfica, verdadeiro símbolo que compõe a paisagem da cidade revestido de inúmeros significados e submetidos à diversas interpretações.

\section{CATEGORIAS ANALIITICAS DOESPAÇOE TURISMO: O EXEMPLO DAFORTALEZA DE SANTACRUZ, NITERÓI/RJ}

Resumo: O objetivo que permeia a presente pesquisa é utilizar a Fortaleza de Santa Cruz, localizada no bairro de Jurujuba, em Niterói, construída em 1555, na entrada da barra da Baía de Guanabara, como foco de análise, ressaltando a importância deste fixo social enquanto atração turística e de lazer, incluindo a cidade de Niterói no circuito destas atividades, complementares à cidade do Rio de Janeiro; além de abordar conceitos e categorias analíticas, oriundos das ciências sociais, principalmente provenientes da Geografia, pertinentes ao estudo das atividades em tela.

Neste contexto, na dinâmica espacial da cidade de Niterói, o processo de mudança de função dos fixos sociais têm sido extraordinário. Residências unifamiliares, prédios e até mesmo fortificações militares, verdadeiras monumentalidades, foram refuncionalizadas, passando por um processo de turistificação. Assim, a refuncionalização da respectiva

${ }^{7}$ Informações obtidas em visita à referida Fortaleza pelo tenente Jefté (Auxiliar de Relações Públicas da Fortaleza de Santa Cruz), em 20/08/2004. 
Fortaleza em espaço cultural torna-se um importante atrativo da história, do patrimônio, da cultura, marcando no espaço urbano sua expressão de monumentalidade, criada pelo homem como símbolo de seus ideais, objetivos e atos, constituindo-se em um legado às geraçóes futuras, formando um elo entre passado, presente e futuro.

Palavras-chave: Espaço e Turismo; Categorias Analíticas, Fortaleza de Santa Cruz.

ANALYTIC CATEGORIES OF SPACE AND TOURISM: THE EXAMPLE OF SANTA CRUZ FORTRESS, NITERÓI/RJ(BRAZIL)

Abstract: This paper focuses on Santa Cruz Fortress, built in 1555 in Jurujuba (Niterói), to guard the entrance of Guanabara bay, and stresses its role as a tourist attraction and leisure area, as a social fix which links the city of Niterói to the complementary circuit of these activities in the city of Rio de Janeiro. The study uses important concepts and analytic categories from social sciences, particularly from Geography.

In the spatial dynamic of the city of Niterói, change in functions of social fixes has been extraordinary. Single-family dwellings, buildings and even military installations have been re-functionalized, undergoing a process of touristification. In that way, the refunctionalization of the Fortress as a cultural space provides an important attraction in the domains of history, patrimony, and culture, providing the urban space with an expression of monumentality, created by man as a symbol of his ideals, aims and actions, a legacy to future generations forming a link between past, present and future.

Keywords: space and tourism; analytic categories; Santa Cruz Fortress.

\section{BIBLIOGRAFIA}

BARRETO, Cristina. 2001. Patrimônio Histórico. In: Turismo e Cultura: a História e os atrativos Regionais. Santo Ângelo: URI/FAPERGS, v.1.

BONNEMAISON, Jöel. 2002. Viagem em torno do território. In: Geografia Cultural: um século (3). Rio de Janeiro: Eduerj.

CHOAY, Françoise . 2001. A alegoria do Patrimônio. São Paulo: Editora UNESP. CORREAA, Roberto Lobato. 1986.. Região e Organização Espacial. São Paulo: Ática.

2005. Monumentos, Política e Espaço. Scripta Nova. Revista Electrónica de Geografía y Ciencias Sociales. Universidade de Barcelona, Vol. IX, n. 183.

COSGROVE, Denis. A geografia está em toda a parte; cultura e simbolismo nas paisagens humanísticas.In CORRÊA, Roberto Lobato; ROSENDAHL, Zeny (orgs.) .1998. Paisagem tempo e cultura. Rio de Janeiro: Eduerj, p.92-122.

EPSTEIN, Isaac .2001.. O Signo. São Paulo: Ática. 7̣a edição. 
Categorias Analíticas do Espaço e Turismo: O Exemplo da Fortaleza de Santa Cruz, Niterói/RJ

FERNANDES, Ulisses da Silva (2004) A Monumentalidade do Hotel Copacabana Palace e o Turismo Global. (Anteprojeto de Pesquisa Mestrado em Geografia). Departamento de Geografia, UERJ.

HARVEY, David. 1996. Condição Pós-Moderna - Uma Pesquisa Sobre as Origens da Mudança Cultural. São Paulo: Loyola.

KOTHER, Beatriz. 2001. Patrimônio Histórico e Turismo. In: Turismo e Cultura: a História e os atrativos Regionais. Santo Angelo: URI/FAPERGS, v.1. LEFEBVRE, Henri. 1999. A Revolução Urbana. Belo Horizonte: UFMG.

LE GOFF, Jacques. 1985. Documento/Monumento. In: Enciclopédia Einaudi. Porto: Imprensa Nacional - Casa da Moeda, v. 1.

LESSA, Carlos. 2000. O Rio de Todos os Brasis: uma reflexão em busca da auto estima. Rio de Janeiro: Record.

LIMA E SILVA, Michel Vieira de. 2005. Desconstruindo Símbolos na Cidade de Deus. (Monografia de Graduação)-Departamento de Geografia, UERJ.

MACHADO, Thiago Ramos. 2003. Cidade e Meio Ambiente em Debate: Notas de Sobre o Papel da Infra Estrutura de Saneamento no Planejamento Estratégico Urbano (inédito).

MARYAN, A. P. 1997. La Salle, o Fugitivo da Fortaleza de Santa Cruz (RJ). 3a ed. Rio de Janeiro.

MELLO, João Baptista F. de. 1995. Explosão e Estilhaços de Centralidade no Rio de Janeiro. Espaço e Cultura n.1, UERJ/NEPEC.

. 2003. Símbolo dos lugares, dos espaços e dos "deslugares". Espaço e

Cultura, n. 16. Rio de Janeiro: Eduerj, julho/ dezembro, p.64-72.

MENESES, José Newton Coelho. 2004. História e Turismo Cultural. Belo Horizonte: Autêntica.

RAHY, Ione Salomão. 1999. Povoamento do Estado do Rio de Janeiro. GeoUERJ, Revista do Departamento de Geografia, Rio de Janeiro n. 6, p. 37-43, jul./dez.

RIEGL, Aloïs. 1984. Le Culte Moderne Des Monuments: Son Essence et As Gênese. Paris: Éditions du Seuil.

RODRIGUES, Cristiane Moreira. 2000. Monumentalidade e Poder na Construção das Cidades: um estudo sobre projetos urbanos não realizados no Rio de Janeiro da segunda metade do século XLX. Dissertação de Mestrado. Rio de Janeiro: UFRJ/PPGG. 2001. Cidade, Monumentalidade e Poder. In: Anais do LX Encontro Nacional da ANPUR. Rio de Janeiro: IPPUR/PROURB/FAU/UFRJ.

SANTOS, Milton. 1985. Espaço e Método. São Paulo: Nobel. - 1988. Metamorfoses do Espaço Habitado. São Paulo: HUCITEC. .1996. Técnica, espaço, tempo. Globalização e meio técnico-científicoinformacional. São Paulo: Hucitec. 
SILVA, Nilton. 2001. De Centro de Defesa a Centro Cultural - A Refuncionalização do Forte de Copacabana. (Monografia de PósGraduação) - Departamento de Geografia, UERJ.

TUAN, Yi-Fu . 1980. Topofilia. São Paulo. DIFEL.

YÁZIGI, Eduardo. 2003. Civilização urbana, planejamento e turismo: discipulos do amanhecer. São Paulo: Contexto.

\section{LOCALIZAÇÃO DOS FORTES E DA FORTALEZA DE SANTA CRUZ NA BAÍA DE GUANABARA \\ Rio de Janeiro}
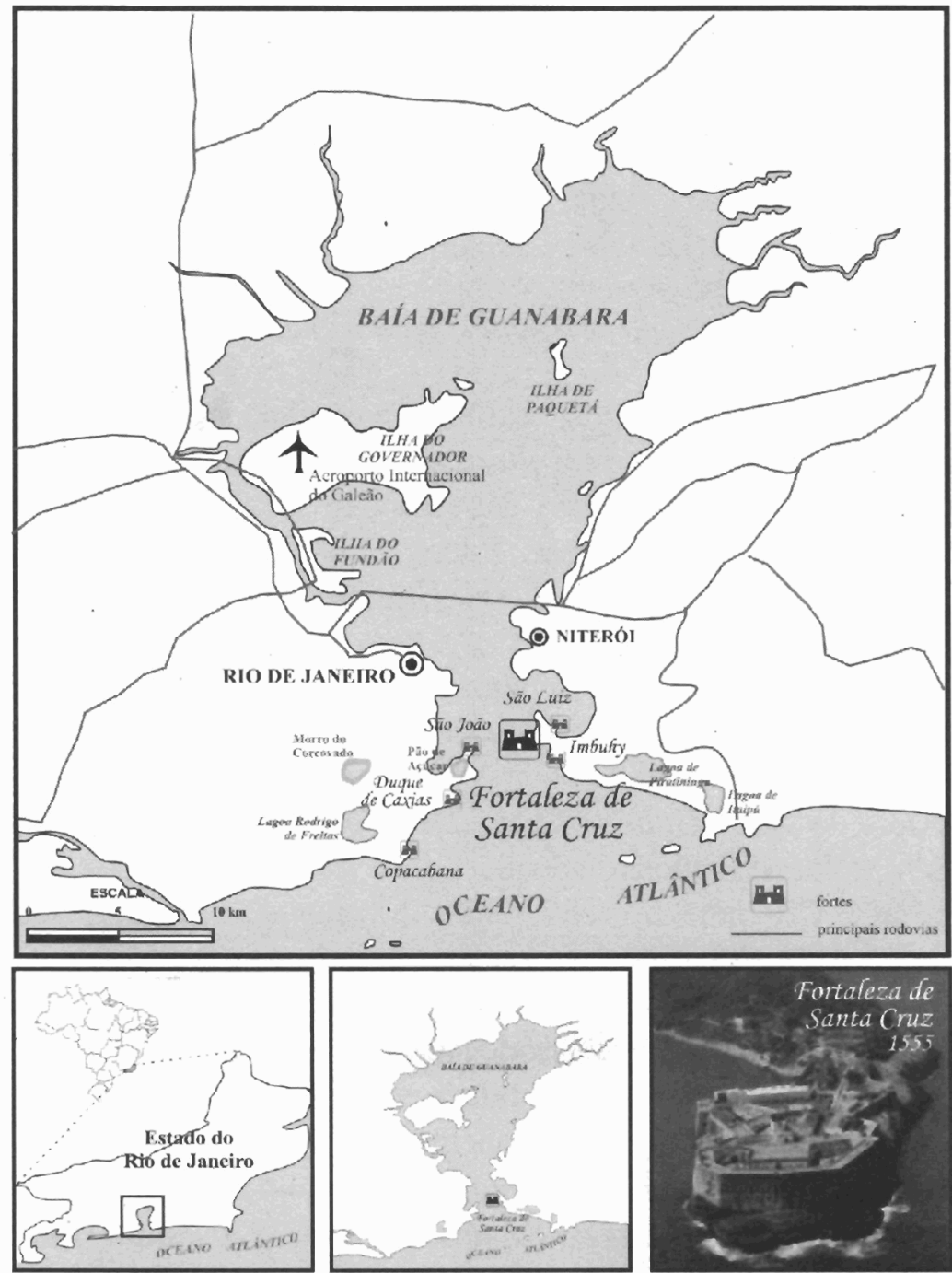

FONTE: LBGE - MAPA DO ESTADO DO RLO DE JANEIRO. 1999

Desenho Grifico: Regina Alonso FOTOS WWWEXERCTTO.GOVBR 